\title{
A Study on the Development of Chinese Lifelong Education System from the Perspective of Cultural Confidence
}

\author{
Jun-ao Chen \\ School of Marxism, East China University of Science and Technology, Shanghai, China \\ Email address: \\ Jachen@ecust.edu.cn \\ To cite this article: \\ Jun-ao Chen. A Study on the Development of Chinese Lifelong Education System from the Perspective of Cultural Confidence. Education \\ Journal. Vol. 7, No. 5, 2018, pp. 127-131. doi: 10.11648/j.edu.20180705.14
}

Received: October 1, 2018; Accepted: November 1, 2018; Published: November 8, 2018

\begin{abstract}
In terms of the proposal of building cultural confidence, the development of lifelong education in China still has a long way to go. Cultural confidence is not only a conception, but the guiding ideology of our country's socialist construction road. This paper mainly discusses the problems and improvement methods in the development of education under the background of cultural confidence. Improvements need to be made in terms of overly westernized theoretical systems, poor connection between teaching resources inside and outside schools and inadequate sharing of resources. Lifelong education is a new demand arising from the changes of times. Based on Chinese traditional culture and the proposal of building cultural confidence, China needs to overcome difficulties and seize opportunities to propel the development of lifelong education, which will promote the improvement and development of Chinese national educational system. To build up cultural confidence and practice cultural confidence in lifelong education and learning culture, the following strategies should be adopted specifically: First is to follow the development of times and turn lifelong education into a mainstream educational mode in the future, Second is to fetch treasures in traditional culture and consolidate the foundation of cultural confidence, Third is to seize the opportunities brought by the proposal of cultural confidence and reaffirm the development of lifelong education and last is to actively explore the effective method of lifetime education of cultural confidence, which included comparative law, the experience method and the fusion way.
\end{abstract}

Keywords: Cultural Confidence, Lifelong Education, Comprehensive Quality

\section{Introduction}

Cultural confidence is the foundation of a country. Developing socialism with Chinese characteristics for life must be rooted in the foundation of cultural confidence. Lifelong learning is the cornerstone of human survival and development. Under the background of cultural confidence, lifelong education and lifelong learning have become the common demand of education development and social progress in various countries. A good education achieves the future. The development of lifelong education system and the establishment of lifelong learning society are the common trends of education development in the world [1].

Since the 18th National Congress of the Communist Party of China, General Secretary Xi has mentioned the concept of cultural confidence in several speeches and pointed out that "we must have full confidence in the path, theory, system, and culture of socialism with Chinese characteristics."
Cultural confidence symbolizes firm affirmation and active practice of the cultural values of a people, a country and a political party as well as the firm confidence in the vitality of its culture. China boasts excellent traditional cultural heritages and continuously develops advanced socialism culture in modern times. The profound traditional culture constitutes the unique concepts of Chinese people. In the current world developing rapidly, the shock western culture has brought on Chinese culture have impacted Chinese people's perception and reflection of culture and led them to recognize the coexistence of Chinese and western culture.

In academia, many scholars have attempted to define cultural confidence differently, while interpretations of the explanations tend to show that cultural confidence includes confidence not only towards domestic culture but also shocks brought by foreign culture. 
In such an environment, lifelong education has spread widely throughout the world as an extremely important educational concept [2]. It refers to the sum of education that people receive during their lifetime and through individual and social lives. Cultural confidence is not only an important concept in the development and inheritance of a lifelong learning culture but also an important guiding principle, and the two aspects are interrelated and both indispensable.

In this regard, what problems and bottlenecks still exist in the development of Chinese lifelong education has become an issue that demands further thinking and discussions.

\section{Problems Looming in the Development of Lifelong Education in China Against the Background of Cultural Confidence}

Against the background of the proposal of building cultural confidence, problems in the development of Chinese lifelong education are as follows.

\subsection{Western Discourses Are Dominant While Chinese Domestic Theories Are Inadequate}

More than 2,000 years ago, the Chinese ancient educator Confucius put forward the idea of exposing education to folk people and proposed that everyone should have equal access to education to encourage people to study diligently throughout their lives [3]. During the Song Dynasty, OuyangXiu also highlighted the importance of continuous learning and practices. However, the ideas did not develop into theories or systems of lifelong education.

The author conducted a sample survey on the current college students' understanding of Chinese traditional culture, and the survey results are shown in Figure 1.

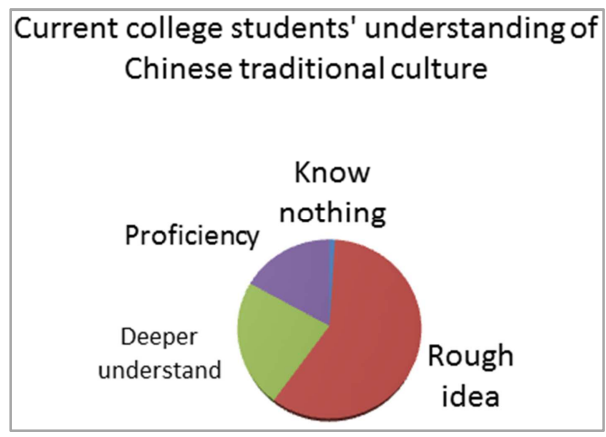

Figure 1. Current college students' understanding of Chinese traditional culture.

Currently, China still adopts the more mature lifelong education theories from the West to guide lifelong education practices. For example, Paul Lengrand from France, father of the lifelong education theory, first introduced the concept of lifelong education in 1965. In 1994, the first World Lifelong Learning Conference was held in Rome, making lifelong learning a consensus around the world. In view of this, western theories are dominant in the evolution of lifelong education concepts, while the Chinese ancient educators' ideas are too rough to be developed into a distinctive theoretical system. The gap has posed severe challenges to Chinese lifelong education system against the background the proposal of cultural confidence: how to position China's lifelong education concept and develop it into a modern educational theory with Chinese characteristics [4].

\subsection{School Education Dominates and Social Education Supplements Remains Hard to Be Changed}

At present, school education still dominates in China, supplemented by social education. However, education is a systematic project, which needs to be completed by families, schools, governments and social communities. In the process of developing sophisticated educational systems, all parties involved should cooperate and fulfill respective responsibilities, exploring different educational priorities from different aspects and adopting different educational methods.

However, viewing from the current trend of the development of Chinese school education and social education, many difficulties and problems are still looming and various types of educational systems are not yet orderly or well-connected despite the continuous integration of the two educational modes.

\subsection{Educational Resources Are Unreasonably Distributed and Inadequately Shared}

Since the development of education needs to follow its own rules and closely keep pace with the times instead of being accomplished overnight, the integration and cohesion of various resources have become an indicator of utilization rates of educational resources in the process.

At present, resources of Chinese lifelong education resources are both inadequate internally and externally during practices. First, the input and supply of educational funds are unbalanced, which leads to insufficient support. Secondly, external resources such as spaces, legal guarantees, and human resources are not fully-fledged so as to meet the current needs of China's lifelong education [5].

In view of the problems of education resource sharing, the author conducted a sample survey on some university teachers and concluded that the difficulties of education sharing were mainly reflected in the following aspects like Table 1.

Table 1. Aspects of education shares hard.

\begin{tabular}{ll}
\hline Aspects & percentage \\
\hline Teaching hardware & $30 \%$ \\
Teacher resource & $25.5 \%$ \\
Quality course resources & $17.8 \%$ \\
EPlatform & $26.7 \%$ \\
\hline
\end{tabular}

\subsection{The Rapid Transformation of Social Environment Has} Made People Fickle

The rapid development and changes of the modern society have made modern people utilitarian and unwilling to spend 
much time and energy on lifelong learning, which could be attributed to the pressure and drawbacks brought by Chinese exam-oriented education for many years. The imperial examination system in ancient China has made the concept that one examination could determine one's life deep-rooted in many people's minds. The rapid development of China's economy in recent years and emergence of new things have also made many people tired of confronting newly emerged things and find it hard to rationally distribute time and energy to make personal lifelong learning plans.

\section{The Approach to Changing Chinese Lifelong Education Against the Background of Cultural Confidence}

Rules of education should be continuously explored and summed up in practices as well as adapted and changed along with the development of the economy and society. In the current environment where building cultural confidence is highly proposed, Chinese lifelong education should also seek development in changes.

\subsection{Follow the Development of Times and Turn Lifelong Education into a Mainstream Educational Mode in the Future}

The rapid development of the current society is unimaginable in the initial stage of lifelong education concept. With the emergence of new terms such as Internet plus, big data and machine learning, existing knowledge cannot satisfy people's interest to explore new things, therefore exposing the limitations of the periodical school education. China is steadily moving towards a learning-oriented society where lifelong education and lifelong learning become increasingly important. Many supporting institutions have been introduced to develop lifelong education into a prevailing ideology.

Lifelong education refers to the sum of education that a person receives throughout his or her individual and social life; it is a humanity-related, social and professional process that a person or group experiences based on the improvement of living standards. It is a comprehensive and unified concept covering all periods and aspects in one's life and aims at promoting inspiration and progress, which is composed of all formal, non-formal and informal learning. Lifelong education is an integration of school education and post-graduation education and training. It not only refers to the development of the relations between formal and non-formal education but also educational-policy-centered elements composed of the maximum cultural and educational goals of individuals (including children, youth and adults) realized through community lives. Researchers generally believe that lifelong education is the sum of various cultivation people receive in their lives. It refers to educational activities in all stages and aspects of individual development throughout one's life, including education of all levels individuals receive in different periods of life ranging from infancy to old age and also education one receives in different fields such as schools, families and the society, Its ultimate goal is to "maintain and improve the quality of individual social life". Therefore, educators need to adhere to the educational principle of "shaping values, fostering abilities and delivering knowledge" and uphold the educational goal of "focusing on education and prioritizing improving the qualities of talents." They should also actively explore, enrich, and promote lifelong learning approaches, adopt comprehensive teaching modes combining heuristic, interactive, flipped classrooms and scenario simulation, and give full play to the main role of students in lifelong learning. Teachers need to integrate and reconstruct teaching content, promote comprehensive reform of teaching contents and methods which aim at improving the quality of and effects of school teaching, and continuously improve the quality and level of talent fostering. In view of this, the trend that lifelong education becomes a mainstream educational mode conforms to changes of times.

\subsection{Fetch Treasures in Traditional Culture and Consolidate the Foundation of Cultural Confidence}

Cultural confidence is closely related to social development [6]. It is undeniable that western lifelong education concepts are more systematic and mature; however, with the development of China and the proposal of building cultural confidence, Chinese people need to be more convinced that the confidence is not only generated by economic prosperity but also the time-honored and excellent Chinese culture lasting over 5,000 years. Throughout the history of Chinese civilization, various ideological systems have been developed. Only in the Spring and Autumn Period and the Warring States Period, there were great thinkers such as Laozi, Confucius, Mozi, Zhuangzi, Mencius, and Han Feizi, contributing to rich ideological and cultural wealth of Chinese people. Since the May Fourth Movement, Chinese people have adopted western thoughts and achieved new breakthroughs of Chinese traditional culture, forming a modern cultural system where traditional Chinese culture was maintained and western technologies were introduced. Since the Reform and Opening-up, Chinese people have developed Chinese roads and models and accumulated distinctive experiences of building China into a modern country based on great practices of continuous exploration and daring innovation. Therefore, cultural confidence is not blind but is based on the profound and long-lasting Chinese culture of 5,000 years and is rooted in the practices of great social changes since the founding of PRC, especially since the Reform and Opening-up.

Against the background of the proposal of building cultural confidence, major work for educators includes refining and improving the above-mentioned concepts and tapping into the theoretical essence of China's lifelong education, which also constitutes the cultural foundation for building a lifelong education system with Chinese characteristic [7].

The main purpose of lifelong education is to foster high-quality citizens through culture. Only by strengthening cultural confidence and fostering pride of citizens towards 
Chinese culture can they voluntarily accept the excellent domestic culture and help achieve the goal of fostering high-quality citizens with excellent Chinese culture. Conversely, cultural confidence cannot be developed in the short term but requires lifelong education and practices. Therefore, strong and deep-rooted cultural confidence needs to be accompanied by continuous and persevering lifelong education.

\subsection{Seize the Opportunities Brought by the Proposal of Cultural Confidence and Reaffirm the Development of Lifelong Education}

Issues such as how educational modes respond to global economic development and how to improve people's comprehensive qualities have become valuable goals of modern education. Since times are changing and so are the requirements of comprehensive qualities, continuous lifelong education needs to be an ultimate goal of education [8].

The report The Future of Lifelong Learning released by the UK points out that time is a factor changing the courses and patterns of lives, especially during the "peak" period of life, that is, ages between 25 and 50 years old. During this period, people not only bear work-related learning pressure but also need to assume obligations as parents, thus making time quite rare. Although adults have no time for continuous learning with only scarce time, they can choose to study online. Instructors can change traditional teaching modes and turn to online classes or provide online materials so that adults can flexibly choose a time for learning and maximize the use of time no matter where they are. Adults can also learn at any time and any place through MOOC or mobile apps. For adults over 50 years old, they can choose community colleges or senior universities to foster more hobbies, cultivate temperament, and improve fitness. They can also learn knowledge related to computers and information processing to keep up with the Information Age.

However, the above-mentioned cultural confidence is not blind confidence but derives from a clear understanding of the value and essence of things, which is a rational attitude based on comprehensive analysis of subjects and objects of things. Chinese lifelong education scholars are full of confidence due to the profound understanding that lifelong education is a newly emerged discipline in response to requirements of times and a unique one that meets social needs with distinctive features with great potentials. The concept of cultural confidence highlighted in China does not exclude advanced foreign academic achievements but actively absorbs relevant useful theoretical viewpoints from abroad based on academic confidence to improve domestic disciplines. Under such a background, educators are striving to build a theoretical system of lifelong education that is rooted in Chinese culture and integrates international concepts.

\subsection{Actively Explore the Effective Method of Lifetime Education of Cultural Confidence}

There are many ways to approach cultural confidence education, which are outlined here in three main ways and effective methods [9].

The first way is comparative law. Cultural confidence depends not only on your writing quality also comes from cultural comparison and cultural tolerance, and cultural comparison. It's a sign of cultural confidence. Comparison is the only way to identify, especially text. There are many different types, and only through comparison can we know their cultural specialties and take long for short. The first cultural comparison is the comparison between eastern and western cultures. Eliminate the prejudice of worshipping things foreign and fawn on foreign countries. The correct attitude is neither belittle nor blind rejection of foreign things, realizes the east and west cultural integration development. The second is to make a good comparison between Marxism and traditional Chinese culture. Eliminate incompatible misunderstandings. With thousands of years of Chinese civilization by contrast, Marxism is not only mutually exclusive, but also mutually known, interconnected and mutually compatible integration and mutual promotion. The process of sinicization of Marxism is the process of integrating Chinese traditional culture, which has realized the nationalization of Marxism, localization. Marxism is only integrated with the traditional Chinese culture, then have abundant cultural nourishment and practical basis.

The second way is the experience method. Cultural confidence comes from recognition of the identity and enjoyment gained by the subject of knowledge for the profound experience of culture. We should strengthen the integration of knowledge and practice, the combination of learning and application, and educate people by writing. There are many ways to experience, social practice, theater performance, debate competition, reading good books, tourism and other methods are popular among the public, the key is to organize well, achieve the unity of content and form, motivation and effect.

The third way is the fusion. In the teaching content, we should realize various cultures, the integration of east and west, inheriting innovation, traditional modernity, elegance and popularity, etc. In terms of teaching methods, it is necessary to realize the transformation of in-class, off-line and off-line roles. Especially the integration of school, family and society should be realized to form a good social atmosphere of cultural confidence education.

\section{Conclusion}

Under the background of the proposal of building cultural confidence, opportunities of reform will be generated if educators can re-examine problems, explore approaches to reforms in the development of China's lifelong education, and seek opportunities and break bottlenecks, which is the very requirement posed by the current era [10]. General Secretary $\mathrm{Xi}$ points out that the current era is one that requires theories and thoughts and will definitely produce theories and thoughts.

Lifelong education amid cultural confidence is not only 
displayed by the development of distinctive lifelong education but also external confidence in the face of shocks brought by western culture. Meanwhile, lifelong learning is essential for maintaining a harmonious and civilized society where people can become active citizens and their creativity can be fostered and the society can gain driving forces for sustainable development. Therefore, closely following the development of China's education and building a lifelong educational system with Chinese characteristics is necessary and fundamental for adapting to the development of national education.

\section{References}

[1] Junmei Wang. Study on the Chinese characteristic education system under the background of cultural confidence $[\mathrm{J}]$. Journal of Hongqi amateur university, xuanwu, Beijing, 2018(03):13-16+26.

[2] Yan Zhang, Yantong Zhang; The special meaning and research trend of lifelong education in China $[\mathrm{J}]$; Education research;2016, 37 (8): 132- 136.

[3] Lintao Liu. The concept, essence and contemporary value of cultural confidence. [J], 2016,(4): 21-24.
[4] Xiaoyan Qi; On the way to cultivate cultural consciousness and cultural confidence $[\mathrm{J}]$; Out-of-school education in China; 2012. 26.

[5] Yuhua Wen; Lifelong education is the foundation for survival in the 21st century [J]; Chinese adults education; 2001.06.

[6] Renzong Yuan; Base on local area and improve cultural confidence [A]; Proceedings of the 2011 academic annual conference of Guizhou writing society [C]; 2011.

[7] Jiang Huang. Cultural confidence leads to lifelong education development [J]. Open learning research, 2017, 22(04):29-32.

[8] Zhonghai Ye. Accelerate the development of a lifelong education discipline with Chinese characteristics with cultural confidence [J]. Lifelong education study, 2017, 28(06):36-38.

[9] Yi Zhu. Strengthen the thinking of lifelong education of cultural confidence $[\mathrm{J}]$. Contemporary continuing education, 2017, 35(04):93-96.

[10] Guoqing Hu. A new development path from the perspective of lifelong learning-- Book review on $<$ lifelong learning from a philosophical perspective $>[\mathrm{J}]$. Journal of Hongqi amateur university, Xuanwu, Beijing, 2018(01):68-72. 